Meta

Journal des traducteurs

Translators' Journal

\title{
Aptitude Testing for Simultaneous Interpretation at the University of Ottawa
}

\section{Sylvie Lambert}

Volume 36, numéro 4, décembre 1991

URI : https://id.erudit.org/iderudit/003383ar

DOI : https://doi.org/10.7202/003383ar

Aller au sommaire du numéro

Éditeur(s)

Les Presses de l'Université de Montréal

ISSN

0026-0452 (imprimé)

1492-1421 (numérique)

Découvrir la revue

Citer cet article

Lambert, S. (1991). Aptitude Testing for Simultaneous Interpretation at the University of Ottawa. Meta, 36(4), 586-594. https://doi.org/10.7202/003383ar
Résumé de l'article

L'article présente et décrit les méthodes utilisées pour l'admission des candidats au programme d'interprétation de l'université d'Ottawa. On explique en détail chaque exercice de l'examen de sélection. On donne ensuite les façons d'analyser l'information ainsi obtenue pour choisir les candidats possédant les qualités nécessaires pour devenir interprète de conférence. 


\title{
APTITUDE TESTING FOR SIMULTANEOUS INTERPRETATION AT THE UNIVERSITY OF OTTAWA
}

SYLVIE LAMBERT

University of Ottawa, Ottawa, Canada

\begin{abstract}
Résumé
L'article présente et décrit les méthodes utilisées pour l'admission des candidats au programme d'interprétation de l'université d'Ottawa. On explique en détail chaque exercice de l'examen de sélection. On donne ensuite les façons d'analyser l'information ainsi obtenue pour choisir les candidats possédant les qualités nécessaires pour devenir interprète de conférence.
\end{abstract}

Problems in the recruitment and training of conference interpreters have been the frequent subject of debate and research by members of the profession (Keiser 1978; Longley 1978; Namy 1978) as well as psychologists and linguists (Weller 1983; Gerver, Longley, Long, and Lambert 1984; 1989; Moser-Mercer 1985; Schweda-Nicholson 1986; and Lambert and Meyer 1988).

What qualities and skills are required for success as an interpreter or as a trainee in the field? Although relatively little empirical research has been carried out on the subject (Weller 1983; Gerver, Longley, Long and Lambert 1984; 1989; Moser-Mercer 1985; and Schweda-Nicholson 1986), there does appear to be some consensus among interpreters and interpreter-trainers as to the types of skills and aptitutes sought in new members of the profession. A survey of articles written by members of the profession, as well as transcripts of interviews with working interpreters suggest some agreement of the following as being essential for success as a trainee or in the profession:

1. Profound knowledge of active and passive languages and cultures.

2. Ability to grasp rapidly and convey the essential meaning of what is being said.

3. Ability to project information with confidence, coupled with a good voice.

4. Wide general knowledge and interests, and a willingness to acquire new information.

5. Ability to work as part of a team.

The object of this paper is to present and describe in some detail the screening instruments used at the University of Ottawa to select applicants seeking admission to the Graduate Diploma Programme. The University of Ottawa's interpretation programme provides professional training in both consecutive and simultaneous interpretation. The curriculum includes compulsory and optional courses, a promotion examination before being admitted into second year, a practicum, and a final examination before a board of examiners. The programme is offered by rotation of courses over two years. It is intended primarily for part-time students, although those who place well in the admittance examination and who are exempted from some introductory courses may be able to undertake the programme on a full-time basis. 
The selection exams include:

1. Shadowing

2. Cloze

3. Sight translation/sight interpretation

4. Memory test (Wechsler)

5. Interview

\section{SHADOWING}

Shadowing is a paced, auditory tracking task which involves the immediate vocalization of auditorily presented stimuli (Neisser 1967) i.e. a word-for-word repetition, in the same language, parrot-style, of a message presented through headphones. This technique has often been used as a means of studying selective attention in cognitive psychology and usually serves to train beginning interpreters to listen and speak simultaneously in one language (in their mother tongue or A language) before attempting to interpret (from a second language, the B language, into the mother tongue).

Listening and speaking simultaneously is an acquired skill, not something interpreters are necessarily born with. Interpreters who do not master this from the outset can develop bad habits: Barik (1973), for example, found that some interpreters try to minimize the amount of speaking time when the delegate is actually vocalizing and compensate by trying, unconsciously or not, to convey as much of the interpretation as possible during pauses in the speaker's presentation, thus yielding a highly uneven and staccato delivery.

Some cognitive psychologists (e.g. Norman 1976) distinguish between two types of shadowing, both of which are viable as selection tests as well as training exercises for beginning interpreters (see Lambert and Meyer 1988; Lambert 1988; Lambert 1989). Phonemic shadowing involves repeating each sound exactly as it is heard, without waiting for a complete meaning unit, or even an entire word, so that the shadower stays "right on top" of the speaker.

The other form of shadowing, known as phrase shadowing, requires that subjects repeat the speech at longer latencies - more precisely from 250 milliseconds upwards and lag behind the speaker, waiting for a chunk, or meaning unit before beginning to shadow, as is the case with simultaneous interpretation.

Both types of shadowing tests can be used to select interpreters although chronologically, phonemic shadowing should be introduced before phrase shadowing. Furthermore, phonemic shadowing serves mainly to determine whether the subject is able to cope with the mechanical aspect of interpretation, that is the ability to listen and speak simultaneously. Once this has been established in the candidate's A and B languages, phrase shadowing can then be used to determine a candidate's ability to lag, although this exercise is more useful to train interpreters, than to select them.

Shadowing can also serve to gauge applicants' command of their B language. Candidates who claim to be perfectly bilingual often perform very differently in the booth during shadowing exercises. More often than not, candidates perform relatively well when shadowing in their mother tongue but stumble, omit words, and become incomprehensible when shadowing a weak B language. Studies in fact have shown that one cannot shadow what one does not understand (Rosenberg and Lambert 1974). In general, a student who is unable to shadow in his or her B language, does not have the linguistic competence required to enter the programme at Ottawa University.

Shadowing exercises can be varied. Speed of input, for example, can easily be manipulated to create more and more stressful situations for the shadower, the rationale 
being that interpreters have to learn how to cope with speakers who read speeches at break-neck speed. Input rates ranging from 90 to 140 words per minute, as well as low to high degrees of redundancy in the source material, along with various types of nativestandard, native-slurred, and non-native accents can be introduced to reflect a pattern of constant increase in difficulty. White noise can also be added to recorded speeches to further impede aural recognition, as is done at Middlebury College for the summer intensive language programme selection test. Finally, as part of the selection examinations at the Polytechnic of Central London, in England, Program Director P.E. Longley deliberately introduced unexpected and sometimes incongruous elements in order to test the applicant's reaction when shadowing unanticipated and extraneous material in the source language text.

2. CLOZE

The cloze procedure is a method of test construction which consists of deleting words from prose, say every 10 th word, and asking subjects to fill in the blanks. The term cloze comes from the psychological concept of closure which is the perception of apparent wholeness of visual or auditory inputs that are actually incomplete. Through closure, the missing parts are ignored or compensated for by projections based on past experience.

The cloze technique was used extensively during experiments on bilingualism and is used increasingly as a test of second-language proficiency. Stubbs and Tucker (1974), for example, are convinced that the cloze technique represents an extremely useful evaluative tool for English as Second Language specialists and pedagogical device for the teacher in the field because it has proven itself to be a good index of general language proficiency, purportedly encompassing lexical, syntactic and semantic aspects of language processing. Since one of the foundations of language skills is the capacity to anticipate elements in sequence, especially when the elements are generated within the confines of time, Oller (1972) felt that the cloze procedure was an excellent device for testing this sort of expectancy. Oller defined the constant role which prediction plays during comprehension of written or spoken language as "expectancy grammar." Anticipation and prediction are constantly called into play during simultaneous interpretation. Furthermore, since one of the foundations of language skills is the capacity to anticipate elements in sequence, especially when elements are generated within the confines of time, e.g. under stress, an aural form of the cloze test was devised by John Long in a study of criteria for selecting conference interpreters (Gerver et al. 1984; 1989). The test can be carried out in a subject's mother tongue as well as in his or her second language, the idea being that the more proficient a person is in a second language, the less difficult it is to cloze on the incomplete material in that language.

In the cloze test, subjects' fill-ins of the blanks can be scored either for the exact word or an acceptable synonym. Stubbs and Tucker (1974) provide an explanation on how to construct and score such a test. Briefly, they recommend that, as is customary, a few sentences be left intact at the beginning and at the end of the passage to provide context. Each candidate's test is scored twice, first for exact replacements and second, for any contextually acceptable alternative. The text can be lifted directly from a newspaper and photocopied with every nth word deleted by using "white out" or by blackening the word with a felt marker, indicating to the subject where the word has been deleted. For our purposes, however, where the material is presented aurally and not visually, the texts are read or recorded by native speakers and the deleted words are replaced by beeps or tones, indicating where the item has been deleted. Every tenth word can be deleted or certain key words can be deleted. The author has suggested elsewhere various ways of 
using the cloze technique as a pedagogical tool for training translators and interpreters (Lambert 1988; 1989).

In the Gerver et al. study (1984; 1989), Long devised three short cloze passages. The first was in English and labelled Cloze 1. It consisted of passages of approximately 500 words. Apart from initial and final sections of about 45 words left intact to provide both context and warm up for the subjects, every 10th word was deleted from the passage. The passage was recorded in English by a native speaker. The candidates were instructed to listen to the texts and to write down, as quickly as possible, the missing words signalled by a tone. The test was scored by counting the total number of exact responses supplied. The text for Cloze 1 was an English translation of part of a French short story entitled "The Beach" by A. Robbe-Grillet (translated by B. Wright, in Lyon, 1966). After the initial testing of candidates had been carried out using this material, it was felt that a translation might introduce extraneous variables into the testing procedure, and two further 500-word passages were constructed, one in English (Cloze 2) and one in French (Cloze 3), neither one a translation.

Results indicated that the auditorily presented cloze-test significantly discriminated passing and failing interpreter students since it involved external pacing and hence speed stress. There can be no doubt that the speaker-paced nature of simultaneous interpretation involves speed stress of the classic kind (Conrad 1954) which suggests that the particular stress experienced by simultaneous interpreters needs to be evaluated with linguistic materials.

For our purposes at the University of Ottawa, the cloze test is also recorded or read viva voce to the candidates. Specific words are deleted and replaced by a tone or a beep to indicate where the deletion has occurred. Applicants are asked to shadow the incoming text and fill in the blanks orally as they shadow. The cloze test is carried out in the candidates' A language first and then in their B language.

The cloze test is a highly versatile tool because not only can it be used to determine one's command of the B language as it was originally designed to do, but it can be adapted to measure other skills, namely interpreting candidates' ability to keep abreast of current national and international affairs as they are encouraged to do once accepted into the interpreter training programme here. To this effect, the following texts will serve as illustrations:

Text A (where every 10th word is deleted):

\section{The Bombs of September}

Wednesday is a busy day for the Tati discount - (store) on the Rue de Rennes in Paris. School is - (out) that afternoon, and mothers, particularly those with modest incomes,

- (flock) to Tati with their children in search of bargains.

- (Thus) the sidewalk in front of the store was bustling

- (last) week at 5:28 p.m., when two black-mustachioed men in

- (a) black BMW drove past.

Text B (where specific words are deleted):

\section{The Bombs of September}

Wednesday is a busy day for the - (Tati) discount store on the Rue de - (Rennes) in Paris. School is - (out) that afternoon, and mothers, particularly those with (modest) incomes, flock to Tati with their children in search of - (bargains). Thus the 
sidewalk was bustling last week at 5:28 p.m., when - (two) black-mustchioed men in a - (black) BMW drove past.

As the car - (slowed) down, the man on the - (passenger) side got out and dropped a - (package) into a trash can near the front door. He quickly - (hopped) back into the car and rode off. A few - (seconds) later, an explosion shattered the happy (sounds) of shoppers. There was simply a noise, very loud, then - (screams) of the people", recalled a - (witness).

(Time, September, 1986)

\section{SIGHT TRANSLATIONSIGHT INTERPRETATION}

Sight translation involves the transposition of a text written in one language into a text delivered orally in another language. Since both aural and visual information processing are involved, sight translation could be defined as a specific type of written translation as well as a variant of oral interpretation.

From a human information processing perspective, sight translation appears to have more in common with interpretation (Moser, personal communication), as a number of variables such as time stress, anticipation, reading for idea clozure, not to mention the oral nature of the task are either absent in written translation, or present only to a limited degree.

Sight translation can also be rendered more or less challenging. An unstressful sight translation would be one where the candidate is allowed ten minutes or so to read over a passage and prepare the vocabulary. A more stressful exercise would be to eliminate the preparation time and ask the candidate to begin translation immediately without even having read the text. This is often done in court interpretation situations, where documents are handed to the court interpreter for immediate translation before the judge.

For the purpose of selecting interpretation candidates, the subject is presented with a typed (i.e. legible) text, first in his or her B language, and, following a brief preparation time of five to ten minutes, is asked to deliver an oral sight translation of the text into his or her A language. Subjects are encouraged to use some basic public speaking skills such as reading ahead so as to anticipate where the sentence is going, chunking information (i.e. reading for idea clozure), handling difficult vocabulary either by paraphrasing or clozing, finishing a sentence once they have begun it rather than start, stop mid-way and start the same sentence over again, and finally speaking clearly, evenly, and convincingly. Once the task is completed, the candidate is then asked to do the same in the other direction, i.e. from his/her $\mathrm{A}$ language into the $\mathrm{B}$ language.

Sight interpretation, as opposed to sight translation, is one step closer to simultaneous interpretation in that the message is presented aurally to candidates as well as visually. In this case, applicants are given five to ten minutes to prepare a written editorial-type speech. Following this preparation, applicants are then asked to deliver a sight interpretation of the editorial as it is being read to them through headphones. Candidates are told to follow the speaker who may or may not depart from the original text from time to time, and not to simply read from the passage as though it were a sight translation exercise.

Although sight interpretation is a difficult task which requires weeks, sometimes months for beginning interpreters to master and is therefore included in the curriculum, we felt that if the material were easy enough and if the passage were read slowly, this type of exercise would be highly useful as a selection test where examiners want to be able to detect whether or not candidates have the interpreting reflex among subjects who cannot yet interpret. Therefore, most of the selection tests employed at the University of 
Ottawa (shadowing, sight translation and sight interpretation) are approximations to simultaneous interpretation and not the final skill per se. We felt that we could not test applicants for a skill they had not yet mastered and for which they were seeking admission.

\section{WECHSLER MEMORY TESTS}

Text memory tests are based on the assumption that interpreters need to remember as well as understand the information conveyed by discourse, that is, store the meaning of the speech. A grasp of the informational structure of a piece of discourse is assumed to facilitate comprehension in the case of simultaneous interpretation and recall in the case of consecutive interpretation.

Two short text memory tests were chosen from the Wechsler Memory Scale (Wechsler 1945). Since these happen to exist in English only, two similar texts were designed in French. All four texts consist of approximately 65 words, which are grouped into precisely 24 "memory units." The candidates are scored in terms of the number of memory units correctly recalled.

The following are examples of one of the original Wechsler memory tests (A) and a translated memory test (Lambert) for our selection purposes at the University of Ottawa:

\section{Memory Selection (A) from Wechsler (1945)}

Anna Thompson/of South/Boston/employed/as a scrub woman/in an office building/reported/at the City Hall/Station/that she had been held up/on State Street/the night before/and robbed/of fifteen dollars/. She had four/little children/, the $\mathrm{rent} / \mathrm{was}$ due/, and they had not eaten/for two days/. The officers/touched by the woman's story/made up a purse/for her.

\section{Memory Selection (Lambert) in French}

Marie Hébert,/la fille/aînée/du boulanger,/a disparu/hier/alors qu'elle rentrait/de l'école,/en bicyclette. /Elle portait/des lunettes/, un imperméable/jaune canari/et ses cheveux/étaient tirés/en queue de cheval/. Si vous l'avez vue/prière de vous adresser/au poste de police/car il y a une récompense/de $\$ 1,000.00$ dollars / pour tout renseignement/sur sa disparition/.

Each of the four memory texts constitutes a means of testing one of four conditions:

1. Wechsler I (A to A), the control condition, tests only retentive ability and involves no code-switching and no testing of the second language. In other words, the first Wechsler text is presented to the candidates in their A language (mother tongue) who are asked to listen attentively, without taking notes, and to subsequently recall as much as possible, in the same language.

2. Wechsler II (B to B) tests both the retentive ability of the candidates, as in the earlier condition, as well as their command of their B language both in terms of decoding (comprehension of the incoming message) and encoding (recall and oral reconstruction of the original message). In this condition, the text is presented to the candidates in their B language and they are instructed to recall as much as they can in the same language.

3. Both Wechsler III and IV conditions test the translation factor, since code-switching (i.e. decoding the information in one language but encoding it in another) is now introduced as a variable. In condition III (B to A), candidates are presented with the third Wechsler text in their B language and are asked to recall as much as possible in their A language. 
4. Finally, in the fourth condition (A to B), candidates hear the fourth Wechsler text presented in their A language and are asked to recall it in their B language. As in condition III, both retentive memory and translation abilities are tested.

\section{THE INTERVIEW}

The oral examinations are followed by private interviews lasting approximately 20 to 30 minutes per candidate. The interviews are normally given by two faculty members who will be training the diploma students, and by the programme director, when available. The aim of the examiners during the interviews is twofold:

a) to ascertain the candidates' abilities in both working languages, and

b) to assess their general knowledge and awareness of current events throughout the world.

Interviews are carried out in both working languages: usually, one examiner interviews in the candidates' A language, while the other interviews in the B language. To put candidates at ease, interviews are generally begun in their mother tongue. Once the interviewer feels $\mathrm{s} / \mathrm{he}$ has conversed with the candidate for a sufficient length of time to assess his / her competence in language $\mathrm{A}$, the interview proceeds in language $\mathrm{B}$. This switch occurs at no specific point during the interview and is left to the discretion of the examiners.

Examiners usually begin by asking candidates about their general linguistic and educational background. For example, candidates may be questioned about previous studies, residence abroad (especially if they know foreign languages), areas of expertise and interest, types of newspapers and magazines read or subscribed to, general political interests, and reasons for wanting to become an interpreter.

Next, candidates are questioned about current events, both in Canada and, in the case of foreign students, in their native country. For example, they may be asked to talk about the most pressing problem(s) facing their country. Questioning may then take other directions: for example, the examiner may select a controversial subject or some item that comes up frequently in the news to see how candidates react. Should candidates encounter difficulties at this point, it is highly unlikely that they will be capable to dealing effectively with unfamiliar subject matter when interpreting.

In order to standardize interviews, candidates are given four topics and are asked to choose on to discuss in their A language and another, in their B language. Topics may vary but the menu consists of both general issues (such as abortion, apartheid, the death sentence) and more specific ones (such as Canadian immigration policies, our tax system, upcoming elections). The candidates are then given 20 minutes to prepare both ropics prior to the actual interview. During the interview, however, they are not to read from notes they may have made for this preparation.

\section{DISCUSSION}

The various screening instruments described above provide the examiners with an understanding of several general characteristics considered important for incoming candidates:

\section{COMMAND OF A AND B LANGUAGES}

All components of the examination indicate to some degree the candidates' command of their working languages; while a high level of competence in the B language is important, a superior command of the A language is a primary requirement for admission into the programme. 


\section{THE ABILITY TO TRANSFER MEANING}

All tests determine the candidates' ability to transfer meaning accurately from one form into another, whether intra- or inter-lingually.

\section{GENERAL KNOWLEDGE}

The general knowledge evaluation carried out during the oral interview indicates the candidates' general knowledge, and particularly their awareness of current events.

\section{PRONUNCIATION AND ENUNCIATION}

All oral components of the examination, to varying degrees, indicate the candidates' ability to pronounce and enunciate in both working languages. Pronunciation is usually a problem for non-native speakers, whereas enunciation often presents difficulties for native speakers. General voice quality plays a major role in the selection process; those who murmur or sound as though they are talking to themselves during shadowing and/or sight interpretation are usually disqualified.

\section{PERSONALITY TRAITS}

All components of the examination indicate, to some degree, two personality traits considered important for successful interpreters. First, candidates must be able to deal with stress. This ability is particularly put to the test by increasing input rates (e.g. during shadowing and sight interpretation tests), and memory tests - all of which create time stress. While occasional incidences of fatigue are considered normal, a significant failure to cope with examination conditions can eliminate a candidate. Furthermore, candidates who persevere during difficult parts of the examination, trying their best to say as much as possible, are viewed more favourably than those who become easily discouraged and who simply give up.

In certain cases, candidates themselves admit an inability to cope with stress and decide not to pursue the admission examination any further. Furthermore, candidates must be able to demonstrate a certain amount of assertiveness: insecure candidates usually sound unconvincing, and as professional interpreters, would probably have trouble convincing audiences. Candidates' level of assertiveness can be measured during all facets of the admission examination (voice and ability to project) as well as during the oral interview (voice, demeanor and reactions).

\section{SPECIFIC INTERPRETATION-RELATED SKILLS}

Two specific components of the oral examination are designed to test two correponding interpretation-related skills. First, the ability to listen and speak at the same time, which is considered crucial for simultaneous interpretation, is evaluated in the shadowing exercises. Second, memory skills (i.e. retentive ability and recall) are evaluated specifically in the memory tests, and to some degree in the general knowledge components of the oral interview.

Based on our experience devising and administering selection examinations at the School if Interpreters at the Polytechnic of Central London with Patricia E. Longley and the late David Gerver, from 1976 to 1979, at the Monterey Institute of International Studies in California from 1979 to 1983 , and at the University of Ottawa, since 1984, we feel that while there seems to be no foolproof predictor of potential interpreters' success, the University of Ottawa's current battery of selection instruments at least appears to discourage or reject those candidates who appear to have little or no chance or ever succeeding in interpretation. In order to verify this impression (which is still at a preliminary stage since the above-mentioned selection tests have only been implemented since 1984 and have already undergone several modifications), we are currently in the 
process of collecting data on the proportion of candidates who apply, take the courses, pass the final examination at the end of the programme, and who go on to become successful interpreters. In short, we hope to gather sufficient data over the next few years to determine whether or not there exists a significant correlation between the results obtained on the above-mentioned selection tests and those subsequently obtained in the Diploma Programme.

\section{BIBLIOGRAPHY}

BARIK, H.C. (1973): "Simultaneous interpretation: temporal and quantitative data," Language and Speech, 16, pp. 237-270.

CONRAD, R. (1954): "Speed stress," W.F. Floyd and A.P. Welford (Eds.), Human Factors in Equipment Design, London, H.K. Lewis.

GERVER, D., LONGLEY, P.E., LONG, J., \& S. LAMBERT (1984): "Selecting trainee conference interpreters: a preliminary study," Journal of Occupational Psychology, 57-1, pp. 17-31.

GERVER, D., LONGLEY, P.E., LONG, J., \& S. LAMBERT (1989): "Selection tests for trainee conference interpreters," Meta, 34-4, pp. 724-735.

KEISER, W. (1978): "Selection and training of conference interpreters," Language, Interpretation and Communication, (Eds.) David Gerver and H. Wallace Sinaiko, New York, Plenum Press, pp. 11-24.

LAMBERT, S. (1986): "The cloze technique as a pedagogical tool for the training of translators and intepreters," Jerome Quarterly, 2-2, p. 13.

LAMBERT, S. (1988): "A human information processing and cognitive approach to interpreter-training. American Translators' Association (ATA) Proceedings," Seattle, Washington, October, Learned Societies Inc., pp. 379-387.

LAMBERT, S. \& MEYER, I. (1988): "Selection examinations for student interpreters at the University of Ottawa," The Canadian Modern Language Review, 44-2, pp. 274-284.

LAMBERT, S. (1989) : «La formation d'interprètes : la méthode cognitive», Meta 34-4, pp. 736-744.

LONGLEY, P.E. (1978); "An integrated programme for training interpreters," D. Gerver and H.W. Sinaiko (Eds.), Language, Interpretation and Communication, New York, Plenum Press.

LYON, P. (1966): French Short Stories, 1, London, Plenum Press.

MOSER-MERCER, B. (1985): “Screening potential interpreters," Meta, 30-1, pp. 97-100.

NAMY, C. (1978): "Reflections on the training of simultaneous interpreters. A metalinguistic approach," D. Gerver and H.W Sinaiko (Eds.), Language, Interpretation and Communication, New York, Plenum Press.

NEISSER, U. (1967): Cognitive Psychology, New York, Appleton-Century-Crofts.

OLLER, J.W. (1972): "Scoring methods and difficulty levels for cloze tests of ESL proficiency," Modern Language Journal, 56, pp. 151-158.

ROSENBERG, S. \& W.E. LAMBERT (1974): Contextual constraints and the perception of speech, Journal of Experimental Psychology, 102, pp 178-180.

SCHWEDA-NICHOLSON, N. (1986): "Screening interpretation candidates at Delaware: a comparative study," Proceedings of the First North American Translators Congress (Mexico, February 26-28, 1986) Medford, New Jersey, Learned Information Inc., pp. 213-229.

STUBBS, J.B. \& G.R. TUCKER (1974): "The cloze test as a measure of English proficiency," Modern Language Journal, 58, pp. 239-241.

WECHSLER, D. (1945): “A standardized memory scale for clinical use," Journal of Psychology, 19, pp. 87-95.

WELLER, G. (1983): “Aptitude testing for simultaneous interpretation," Paper presented at the TIES Symposium, Provo, Utah, April 27-30. 